\title{
Harnessing smart technology for private well risk assessment and communication
}

\author{
Tanner Hoffman \\ Public Health Ontario \\ Paul Hynds \\ Technological University Dublin, Paul.Hynds@tudublin.ie \\ Corinne Schuster-Wallace \\ University of Saskatchewan
}

See next page for additional authors

Follow this and additional works at: https://arrow.tudublin.ie/ehsiart

Part of the Environmental Engineering Commons, and the Medicine and Health Sciences Commons

\section{Recommended Citation}

Tanner Hoffman, Paul Hynds, Corinne Schuster-Wallace, Sarah Dickson-Anderson, Anna Majury, Harnessing smart technology for private well risk assessment and communication, Water Security, Volume 6, 2019, 100026, ISSN 2468-3124, DOI: 10.1016/j.wasec.2019.100026.

This Article is brought to you for free and open access by the ESHI Publications at ARROW@TU Dublin. It has been accepted for inclusion in Articles by an authorized administrator of ARROW@TU Dublin. For more information, please contact arrow.admin@tudublin.ie, aisling.coyne@tudublin.ie,gerard.connolly@tudublin.ie. Funder: Public Health Ontario; Empire Life 


\section{Authors}

Tanner Hoffman, Paul Hynds, Corinne Schuster-Wallace, Sarah Dickson-Anderson, and Anna Majury

This article is available at ARROW@TU Dublin: https://arrow.tudublin.ie/ehsiart/27 


\title{
Harnessing smart technology for private well risk assessment and communication
}

\author{
Tanner Hoffman a,g, Paul Hynds ${ }^{\mathrm{c}, *}$, Corinne Schuster-Wallace ${ }^{\mathrm{d}}$, Sarah Dickson-Anderson ${ }^{\mathrm{e}}$, \\ Anna Majury ${ }^{\mathrm{a}, \mathrm{b}, \mathrm{f}}$ \\ ${ }^{a}$ Public Health Ontario, Kingston, Ontario K7L 3K2, Canada \\ ${ }^{\mathrm{b}}$ Department of Public Health Sciences, Queen's University, Kingston, Ontario K7L 4V6, Canada \\ ${ }^{\mathrm{c}}$ Environmental Sustainability \& Health Institute, Technological University Dublin, Dublin, Ireland \\ ${ }^{\mathrm{d}}$ Department of Geography and Planning \& Global Institute for Water Security, University of Saskatchewan, 121 Research Drive, Saskatoon, Saskatchewan S7N 0X4, \\ Canada \\ ${ }^{\mathrm{e}}$ School of Engineering, McMaster University, 1280 Main St W, Hamilton, Ontario L8S 4L8, Canada \\ ${ }^{\mathrm{f}}$ School of Environmental Studies, Queen's University, Kingston, Ontario K7L 4V6, Canada \\ ${ }^{g}$ Ugandan Water Project, 1679 Dalton Road, Lima, NY 14485, USA
}

\section{A R T I C L E I N F O}

\section{Keywords:}

Mobile technology

Groundwater

Private wells

Risk assessment

Monitoring

Knowledge translation

\begin{abstract}
A B S T R A C T
Unregulated, privately owned water supplies, including groundwater wells, are relied upon extensively, particularly in rural and remote regions. While adequate stewardship behaviors (water testing, treatment, and maintenance) have been shown to decrease the incidence and frequency of faecal indicator organism (FIO) presence and, by extension, the risk of pathogenic ingress, contaminated private water supplies continue to constitute a significant public health risk. Recognizing that innovative approaches are needed to bolster well stewardship, this paper identifies and assesses 35 tools (smartphone and web-based applications) to better understand components, functionality, strengths, and weaknesses. Applications for both data collection and risk communication were identified; however, none adequately assess(ed) risk using space-, time- or source-specific inputs (local hydrogeology, climate, groundwater reliance). Well designed applications integrated with crowdsourced data, environmental data, and models of risk provide an opportunity for enhanced stewardship of private well water resources.
\end{abstract}

\section{Introduction}

Access to a reliable supply of safe drinking water is both a basic human right [15] and a powerful environmental determinant of health [18]. The importance of safe drinking water is widely recognized, yet occurrences of waterborne disease continue to occur regularly in both developing and developed regions [39]. While water contamination remains a concern in all regions of the world, recent research has shown that increased risks are frequently associated with the susceptibility of private (unregulated) groundwater supplies to contamination by enteric pathogens $[20,39,1]$. Unlike residents receiving water from regulated public networks, private well users are typically responsible for maintaining, treating, and potentially upgrading their own systems, as well as water quality monitoring, all of which place a burden on both time and financial resources.

Private well owners frequently fail to test their water at appropriate intervals, with many failing to test at all $[36,37]$, thus increasing their health risk through unknown exposure to waterborne pathogens. In the Republic of Ireland, Hynds et al. [22] documented that increased watersource knowledge among well owners corresponded to an increased likelihood of testing. Similarly, Kreutzwiser et al. [29] reported that increased awareness of contamination risks among well users in Ontario, Canada was correlated with improved well maintenance activities. Increases in testing frequency have also been documented when well owners are aware of local water quality problems [13]. In focus groups conducted by Jones et al. [26], private well owners expressed support for an accessible mapping and data sharing system that would encourage well water testing. Chappells et al. [5] found similar support for a system for dissemination of well contamination information. Given that a lack of knowledge represents a significant barrier to stewardship [6], it follows that appropriate communication can facilitate and encourage desired behaviors. For example, it has been recommended that private well owners be provided guidance regarding how often they should test their water, what they should test for, and

\footnotetext{
* Corresponding author at: Environmental Sustainability \& Health Institute, Technological University Dublin, Grangegorman, Dublin 7, Ireland.

E-mail address: hyndsp@tcd.ie (P. Hynds).
} 
where they can submit samples [38].

To date, several communication strategies have been utilized to disseminate well stewardship information, most of which have reported limited success. An investigation of arsenic risk exposure among private well users in Nova Scotia, Canada, found that official government factsheets were largely failing to reach well owners [5]. In Ireland, Hynds et al. [24] investigated the efficacy of a national hydrological risk communication strategy (focused on domestic wastewater treatment systems) comprising several dissemination methods. Overall, this campaign only increased awareness modestly, with little or no behavioural change found. In part, this can be explained by the campaign's design, a sweeping information push without adequate regard for the existence of numerous target demographics. Studies have found deficits in well-stewardship knowledge most prominent among younger well owners, Refs. [26,37], indicating that knowledge translation strategies aimed at younger demographics are required.

In 2016, an expert panel convened by the National Centers for Disease Control and Prevention (CDC) recommended development and implementation of novel private well stewardship outreach and intervention strategies [14]. According to Hynds et al. [23], "bottom-up" approaches, whereby well stewardship is facilitated via "pocket technologies", may offer a path forward, particularly with respect to younger individuals and households. More recently, the Sustainable Development Goal (SDG) 6 Synthesis Report noted an innovation deficit in water management, calling for increased use of data and smart technologies to address global water challenges [48]. Accordingly, this scoping review sought to i) identify existing smartphone applications (apps) and web-based tools pertaining to water quality and health, ii) assess the thematic scope and technical capabilities of those existing tools, including technical limitations and omissions, and iii) offer recommendations for the design, functionality, and evaluation of future tools for private well stewardship. The resulting recommendations are intended to guide the development of water-related smartphone apps, specifically those for private well stewardship.

\section{Methods}

To identify the nature and extent of available evidence, a global scoping review was undertaken. Scoping reviews provide a preliminary assessment of the potential size and scope of available literature, including ongoing research [19]. The primary research question guiding the review was:

What smartphone apps and web-based tools are available to nonexperts that pertain to the impact of water quality on human health?

For the purposes of this investigation, "tools" were defined as i) smartphone apps, or ii) webpages that present real-time data or permit user entry of source-specific data for tailored information (i.e. not strictly repositories of informational material or official monitoring programs). "Non-experts" refer to those who would use the tool outside of a professional or specialist context. While the initial focus was on tools addressing the impact of water quality on human health, a preliminary review of the literature revealed a paucity of smartphone apps $(n=5)$ devoted to water quality-related health risks. Consequently, inclusion criteria (Table 1) for apps were expanded to include those related to ecological water quality and watershed management, while criteria for web-based tools were limited to those pertaining to both water and health (i.e. water-related health). Given the sheer number of health-related apps available (e.g. fitness, medication adherence, selfdiagnosis, etc.), expansion into the health domain was avoided.

Since this review sought to identify tools for use by non-experts, most of which are not discussed in academic literature, preliminary searches were undertaken using the Google search engine, the most frequently employed global internet search engine [8], and most likely point of contact for non-experts seeking tools of interest. A total of 20 searches using different search term combinations (Table 1) were completed on August 15th, 2018. Search terms were informed by the explicit research question and a preliminary review of available resources. A grey literature representative sampling search strategy analogous to that used by Godin et al. [17] was employed; the title and associated "snippet" (short text description) of the first 100 results for each search were reviewed, equating to 2000 "snippet" reviews. The authors acknowledge that, despite best intentions, an unknown number of tools may have been overlooked given the sheer extent of the worldwide web and locally relevant tools not established to be highly visible online. Despite this limitation, the chosen approach ensured relevance, manageability, and captured all tools readily available for public use. Though unlikely comprehensive, the authors believe a highly representative "snapshot" (approaching comprehensive) was attained.

Of the 2000 search results screened for specific reference to a tool, 336 were deemed to contain potentially relevant content (Fig. 1). Upon exclusion of duplicates and irrelevant tools, 96 unique tools remained. Once selected for further review, a secondary search was completed for each tool using both Google and Google Scholar to identify available supplementary literature. Four additional tools of interest were identified during this search and subsequent literature review, resulting in 100 unique references being assessed for eligibility (i.e. non-expert, water-related). Of these, 65 were excluded based upon the following exclusion criteria: lacking thematic relevance $(n=44)$, developed for professional use $(n=11)$, lacking adequate information (e.g. tool was mentioned, but no description could be found) for full review $(n=10)$.

Through an iterative process based on the tools themselves, data for 18 variables pertaining to tool features and technical components (Supplement 1) were extracted from all available sources, including tool use (where possible). Extracted data were managed within MS Excel $\subseteq 2$ 2016, and tools were categorized by 11 prominent technical features (Table 2).

\section{Results}

In total, 35 tools met the inclusion criteria (Supplement 2). These tools reveal significant diversity in the thematic focus, degree of user interaction, and technical complexity of available tools, including features pertaining to: data entry, data modeling, GPS, visuals and maps, registration, social media integration, and reminders (Supplement 1). Two broad classes emerged, namely i) those designed for data collection $(n=22)$, and ii) those dedicated to risk communication $(n=13)$ (Fig. 2). Each class is further divided into four categories according to functionality: smartphone apps, interactive websites, data entry mechanisms, data types, data sharing, and outputs and interactions (Fig. 2, Table 2).

Smartphone apps involving participation of citizens in water-related data collection represent nearly two thirds of the tools documented, while no data collection tools employed website-based technology. Thematically, these smartphone tools pertain to water quality, stream depth, and water table level (Supplement 2). Among four of the seven apps supporting in-situ scientific analyses, supplementary water quality test kits and materials can be purchased $(\mathrm{n}=3)$ or are provided $(\mathrm{n}=1)$, with common analytes including $\mathrm{pH}$, temperature, nitrate levels, and turbidity. Among data collection tools generally, two use water images to assess water quality while others capture images of water sources and GPS data to enable location-specific analyses. Many apps employ unique strategies to engage users and promote participation. For example, some allow users to share data on social media accounts; others have "gamified" their apps by facilitating competition and rewarding participation. Nearly half of identified tools make data publicly available, frequently using maps. Most data collection tools request or require registration/login to improve user experience by saving user data and preferences. While smartphone apps are the most common data collection tool, they are not used exclusively. Two short messaging service (SMS) based data collection tools were documented, 
Table 1

Criteria used to define tool inclusion and exclusion, with 20 search terms combinations used in the scoping review search strategy.

\begin{tabular}{|c|c|c|c|}
\hline Criterion & \multicolumn{2}{|l|}{ Inclusion Criteria } & Exclusion Criteria \\
\hline Year of tool development & \multicolumn{2}{|l|}{ Any } & None \\
\hline Language (literature) & \multicolumn{2}{|l|}{ English } & Non-English \\
\hline Tool audience & \multicolumn{2}{|l|}{ Non-expert } & Professionals/Specialists \\
\hline Information availability & \multicolumn{2}{|c|}{ Sufficient to extract relevant features/components } & Sufficient to extract relevant features/components \\
\hline App type & Smartphone-based & Website-based & Downloadable excel spreadsheet \\
\hline Theme & $\begin{array}{l}\text { Water quality-related health risks } \\
\text { Microbial water quality } \\
\text { Ecological water quality } \\
\text { Watershed management }\end{array}$ & $\begin{array}{l}\text { Water quality-related health risks } \\
\text { Microbial water quality }\end{array}$ & Swimming pool or hot-tub \\
\hline
\end{tabular}

('water') AND ('citizen science' OR 'crowdsource')

('water' OR 'groundwater') AND ('quality' OR 'risk') AND ('application' OR 'smartphone app' OR 'tool')

('water') AND ('citizen science' OR 'crowdsource') AND ('application' OR 'smartphone app' OR 'tool')

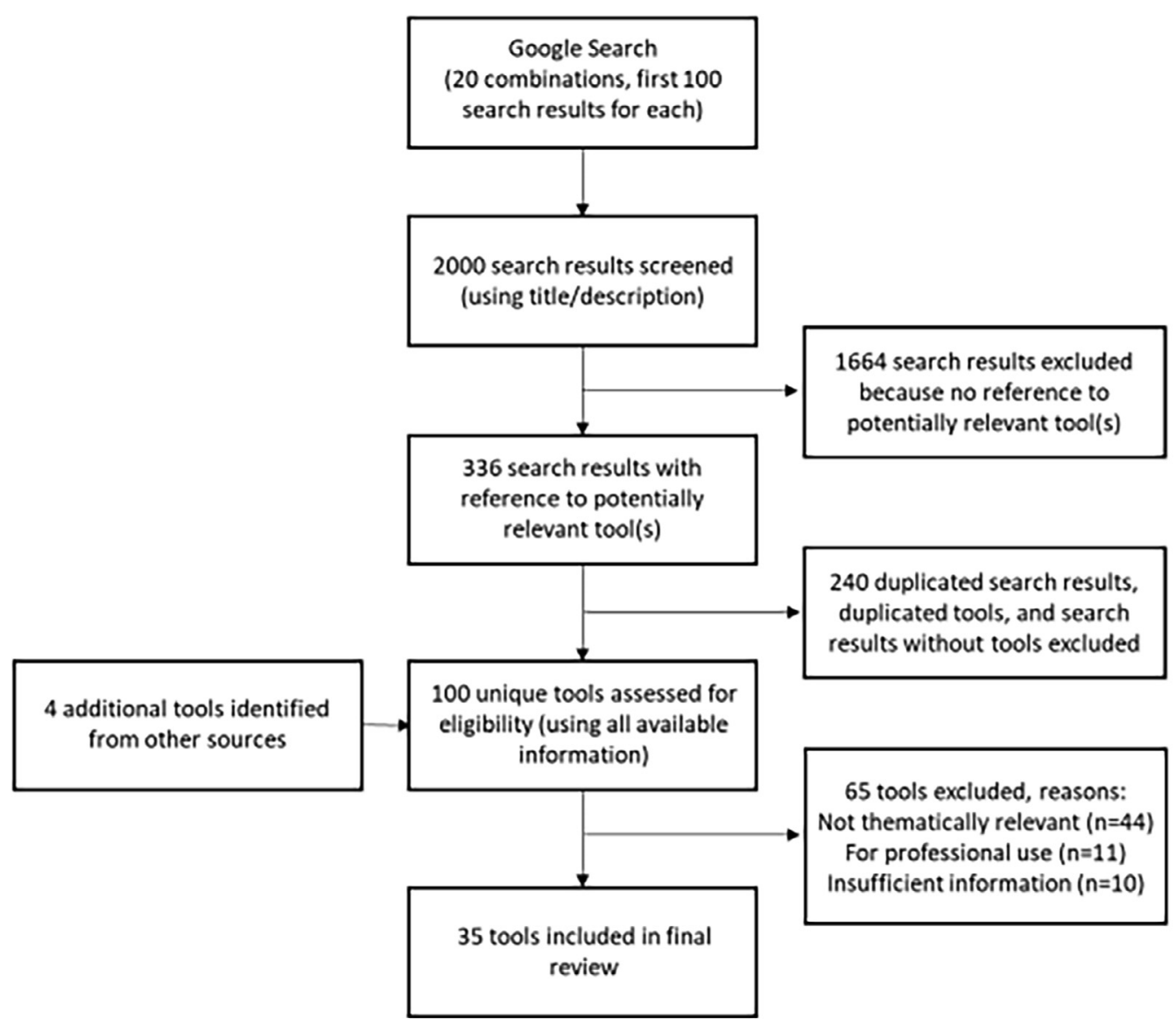

Fig. 1. Review protocol employed during current study including results of literature identification, relevance screening and inclusion/exclusion criteria.

both of which involve citizens observing stream depth using in-situ gauges. For one tool (CrowdHydrology), SMS was selected instead of a smartphone app due to the relative simplicity and ubiquity of SMS, and apprehension that implementation complexity associated with smartphones would inhibit spontaneous participation in opportunistic citizen science endeavors [12].

In the risk communication domain, eight interactive websites without accompanying apps were documented, six of which are dedicated to drinking water quality, primarily groundwater (Supplement 2). These tools require user input of water test results and/or private well characteristics, with users subsequently receiving generalized outputs regarding potential health risks and recommendations for contamination mitigation. In this domain, each water quality-related tool permits user input of standard FIO testing data and provides subsequent result interpretation. For example, the Rural Water Quality Information Tool (RWQIT) is an interactive website which interprets FIO test results, among other chemical and physical parameters [10]. After users enter their test results into the program, RWQIT identifies areas of risk on a parameter specific level and reports that risk using colour coded symbols (Elgert, 2015). If water quality does not meet the Canadian federal water quality guidelines, information pertaining to water treatment and source protection is provided. It is worth noting that only three identified tools are equipped to interpret results of direct enteric pathogen enumeration. All three tools interpreted results for two pathogens, Giardia lamblia and Cryptosporidium, effectively acknowledging the high costs and low levels of available data associated with enteric pathogen 
Table 2

Descriptions of the defining features used for tool classification, including a matrix of category-specific features (Categories 1-8 in Table 2 correspond with categories 1-8 in Fig. 2).

\begin{tabular}{|c|c|c|c|c|c|c|c|c|c|}
\hline \multirow[t]{3}{*}{ Defining Feature } & \multirow[t]{3}{*}{ Description } & \multicolumn{8}{|c|}{ Categories } \\
\hline & & \multicolumn{4}{|c|}{ Data Collection } & \multicolumn{4}{|c|}{ Risk Communication } \\
\hline & & 1 & 2 & 3 & 4 & 5 & 6 & 7 & 8 \\
\hline Smartphone App & Smartphone app is available for data collection or risk communication & $\checkmark$ & $\checkmark$ & $\checkmark$ & & & $\checkmark$ & $\checkmark$ & $\checkmark$ \\
\hline SMS Data Entry & Data collection is completed using SMS data entry (no smartphone app) & & & & $\checkmark$ & & & & \\
\hline Interactive Website & Risk communication is conducted using an interactive webpage (no smartphone app) & & & & & $\checkmark$ & & & \\
\hline Public Data Sharing Portal & Data collected using the tool can be viewed on a publicly accessible webpage & $\checkmark$ & $\checkmark$ & & & & & & \\
\hline No Public Data Sharing Portal & Data collected using the tool is not accessible to the public via a webpage & & & $\checkmark$ & & & & & \\
\hline Warning System & $\begin{array}{l}\text { Real time water quality information (FIO-based) sourced from professionals is made } \\
\text { accessible to the public }\end{array}$ & & & & & & $\checkmark$ & & \\
\hline Evidence Repository & Evidence such as guidelines, recommendations, etc. is synthesized and presented to users & & & & & & & $\checkmark$ & $\checkmark$ \\
\hline Visual Observation & $\begin{array}{l}\text { Data is collected by users making visual observations, but not performing analyses on } \\
\text { physical characteristics }\end{array}$ & $\checkmark$ & & & & & & & \\
\hline Physical Analyses & $\begin{array}{l}\text { Data is collected by users conducting physical (including FIO) analyses, often supplemented } \\
\text { by visual observations }\end{array}$ & & $\checkmark$ & & & & & & \\
\hline Reminder Service & $\begin{array}{l}\text { Reminders for behaviors (i.e. water testing, well maintenance) can be scheduled and sent to } \\
\text { users }\end{array}$ & & & & & & & $\checkmark$ & \\
\hline \multirow[t]{2}{*}{ Decision Tree } & Users answer a series of questions, leading to a "diagnosis" and recommendations & & & & & & & & $\checkmark$ \\
\hline & Number of tools in category & 10 & 7 & 3 & 2 & 8 & 3 & 1 & 1 \\
\hline
\end{tabular}

enumeration in both surface and groundwater.

Two interactive risk communication websites provide water quality information for recreational surface waters. The data presented are sourced from local authorities and use existing FIO records to forecast future water quality status. Thematically comparable to these interactive webpages, three smartphone apps exist to relay recreational water quality information to users. These apps also disseminate water quality information sourced from monitoring completed by local authorities. When tests for a specific location indicate adverse water quality, risk information is communicated to users via the smartphone app. Two smartphone apps that serve primarily as evidence repositories for reference by users were also noted, both of which pertain to drinking water, with one specific to private wells. While these apps largely mirror traditional web-pages, the Well Owner App includes a scheduling feature for water testing, well maintenance, and source protection. Know Your H20?, The second evidence repository app, employs a decision tree based on solicited user information, generalized scientific principles, and regulatory standards.

Among tools meeting the eligibility criteria, a lack of reported evaluations was noted. Just 10 tools (29\%) were described in peer reviewed academic literature, conference proceedings, or conference abstracts. Formal evaluations of any kind were only documented for seven tools (20\%) (Table 3), with the tool interface investigated in just one study (3\%).

\section{Discussion}

Presently, more than half of the world's population use the internet and two-thirds use mobile phones, of which approximately half are characterised as 'smart' devices [27]. With smartphones contributing to a greater share of web traffic than all other devices combined [27], a significant opportunity exists to employ smartphone-based technologies as both risk assessment and knowledge translation mechanisms for private well stewardship. While access to technology, including smartphones and associated apps, is increasing globally [27], global discrepancies regarding access to smart technologies prevail. For example, gaps in access fall along gender and age groups. In low-income countries where only $20 \%$ of men use the internet, women's access is $6 \%$ lower [25]. Moreover, while more than $70 \%$ of youth (age 15-24) are online globally, it is estimated that less than $10 \%$ of people over the age of 75 are connected to the internet compared to an overall access average of $48 \%$ [25]. Geographic inequalities are also prominent. Specifically, mobile-broadband subscriptions and internet use are at least double in high income countries as compared to low- and middle-

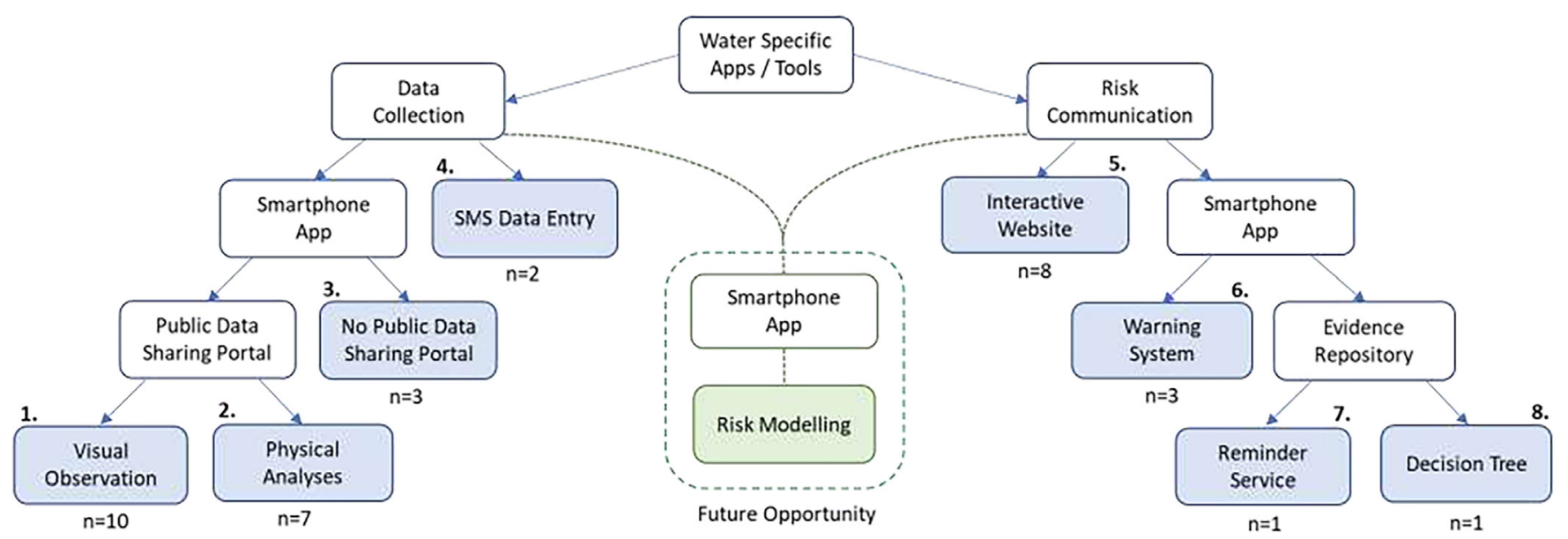

Fig. 2. Flow chart of 35 documented tools delineated into eight categories according to technical capabilities (e.g. inputs, outputs, form, platform), highlighting future opportunity for the development of a ninth category that combines data collection and risk communication. 
Table 3

Summary of evaluations for documented tools, including tool name, evaluation focus (i.e. data quality, scope of use, tool interface), primary evaluation findings, reference, and reference type.

\begin{tabular}{|c|c|c|c|c|c|c|}
\hline \multirow[t]{2}{*}{ Tool Name } & \multicolumn{3}{|c|}{ Evaluation Focus } & \multirow[t]{2}{*}{ Primary evaluation findings } & \multirow[t]{2}{*}{ Reference } & \multirow[t]{2}{*}{ Reference Type } \\
\hline & Data Quality & Scope of Use & Tool Interface & & & \\
\hline Crowd Hydrology & $\checkmark$ & $\checkmark$ & & $\begin{array}{l}\text { 1) Stream gauge location influenced amount of data submitted } \\
\text { 2) A single motivated user submitted substantial percentage of data } \\
\text { 3) Crowdsourced data for stream level is accurate }\end{array}$ & [35] & Peer-Reviewed Journal \\
\hline TransWatL & $\checkmark$ & $\checkmark$ & & $\begin{array}{l}\text { 1) Substantial engagement ( }>1000 \text { measurements in first year) } \\
\text { 2) SMS data entry reduced barriers to participation } \\
\text { 3) Crowdsourced data is similar quality to automatic radar data }\end{array}$ & {$[50]$} & Peer-Reviewed Journal \\
\hline HydroColor App & $\checkmark$ & & & $\begin{array}{l}\text { 1) Data is most accurate when collected under certain favorable } \\
\text { conditions } \\
\text { 2) Various app improvements are needed to improve data quality }\end{array}$ & [32] & Peer-Reviewed Journal \\
\hline CrowdWater & $\checkmark$ & & & $\begin{array}{l}\text { 1) Volunteers generally estimate the relative water level accurately } \\
\text { 2) Overall, crowdsourced streamflow data is highly uncertain }\end{array}$ & [49] & Conference Abstract \\
\hline \multirow[t]{2}{*}{ CreekWatch } & & & $\checkmark$ & $\begin{array}{l}\text { 1) Data was useful for managers and posed few barriers to entry for } \\
\text { users } \\
\text { 2) Users want to filter the data, download it, view it on map and in list } \\
\text { 3) Minor adjustments to the app interface (i.e. button size) required }\end{array}$ & {$[28]$} & Conference Proceedings \\
\hline & $\checkmark$ & $\checkmark$ & & $\begin{array}{l}\text { 1) Global engagement ( }>2000 \text { reports in first two years) clustered } \\
\text { around cities } \\
\text { 2) Data submission more likely when streamflow is higher } \\
\text { 3) User observations correlated with documented flow percentiles }\end{array}$ & [11] & Conference Abstract \\
\hline \multirow[t]{2}{*}{ FreshWater Watch } & $\checkmark$ & $\checkmark$ & & $\begin{array}{l}\text { 1) } 30 \% \text { of volunteers trained participated in data collection } \\
\text { 2) A few engaged volunteers contributed majority of data } \\
\text { 3) Crowdsourced data quality was comparable to laboratory quality }\end{array}$ & [45] & Peer-Reviewed Journal \\
\hline & $\checkmark$ & $\checkmark$ & & $\begin{array}{l}\text { 1) Global engagement ( }>15,000 \text { datasets, }>2000 \text { users) } \\
\text { 2) Most use in France, Singapore, and the UK } \\
\text { 3) Variation in engagement, data quality, and procedures between } \\
\text { countries }\end{array}$ & {$[34]$} & Conference Abstract \\
\hline Eyeonwater & $\checkmark$ & & & $\begin{array}{l}\text { 1) Several problems that can affect data quality were encountered } \\
\text { 2) More attention should be given to these problems in future work }\end{array}$ & [40] & Peer-Reviewed Journal \\
\hline
\end{tabular}

income countries [25]. There is similar evidence of urban versus rural divides, with rural residents experiencing lower access [25]. Apart from two tools developed for use in India and Kenya, those identified here were designed primarily for use in high income regions. A skew towards English language tools was also noted. While these trends likely mirror the true nature of available tools, they may reflect bias in the review methods, which relied on English keywords and only considered literature available in English.

Several lessons can be drawn from the array of tools described, including awareness of the advantages and disadvantages of documented tool features (Table 4). Among tools assessing and communicating drinking water-related risks, an overarching limitation is that they provide users generalized evidence that fails to adequately consider space, time, and source-specific characteristics. None consider the specific geographic location of the water source in terms of hydrological, climatic, geological, and biological contexts. It is essential that future water security-related apps utilize geographic information to provide users spatiotemporal-specific recommendations, as water contamination is time-dependent and significantly associated with geographic place. Elucidating this point, Hynds et al. [21] found that the risk of private groundwater contamination is influenced by several factors linked to land use, geology, and climate, including: local bedrock type, local subsoil type and depth, septic tank setback distance, and local antecedent precipitation. Access to an accurate geographic identifier is thus necessary for reliable collation (via automation or user-input) of these variables, and ultimately for informing risk assessments and spatiotemporally specific mitigation [30].

While the classification system that emerged can be applied to chart commonalities and differences between existing tools in other domains, it was used here to identify gaps in application functionality as they pertain to the needs of private well owners. A key gap is that no existing water-related smartphone apps combine data collection and risk communication capabilities to provide users with context-specific risk assessments, recommendations, and information (Fig. 2). Interventions supporting knowledge translation can play a valuable role in private water source management [41]. While none of the applications were comprehensive from this perspective, the scheduling feature for water testing, well maintenance, and source protection is notable, as reminders for water testing have been suggested as a mechanism by which private well water testing frequency can be increased $[26,29]$. Centralised information repositories, educational resources, and water professional directories are also useful and convenient resources for private well owners to engage with.

Guided by insights derived from the tools reviewed here, including their strengths, weaknesses, and gaps, elements of an ideal tool to support enhanced private well stewardship have been developed (Table 5). Any tool needs to be functional across iOS, Android, and webbased platforms, and capable of multiple language support. A user account is important not only to store individual profiles for return visits, but also to protect the privacy of individuals and their data, particularly when utilizing water quality and geographical location data. A start-up survey provides the necessary baseline assessment and context upon which risk profiles can be built. While many tools use GPS coordinates for location, these need to be used to the maximum extent to harness the use of pertinent external geospatial databases (e.g. weather, land use). Data entry can be used to upload, store, retrieve, and remind. Back-end risk models are important value-adds to convert inputted data into useful information for end users. Notifications support awareness and positive behaviour change through alerts and reminders. The additional provision of a resource repository aids users in accessing timely and trustworthy information.

Conceptually, a coupled-systems approach to enhancing private well stewardship has been articulated [9] that combines geospatial pathogen transport models with user knowledge and practices to inform the development of an interactive app for well users and public health professionals. An app currently under development that begins to close this gap is the Groundwater Risk Application for Local Evaluation (GRAppLE), which will allow users to both enter data and receive 
source-specific contamination risk assessments [23] based on a simplified regression-based risk model. GRAPpLE will concurrently employ smartphone GPS functionality to capture the user's location, permitting retrieval of local model inputs (groundwater vulnerability, subsoil type, bedrock geology, and antecedent precipitation) from validated shapefile datasets and weather networks.

The relative absence of evaluations in the literature (Table 3) makes it difficult for those seeking to develop future tools to learn from the experiences of previous projects, and for designers to iteratively improve their tools. It also indicates that tool evaluation is underappreciated in the overall tool development and implementation process. To fill this gap, mechanisms for future evaluations should be considered by those seeking to develop and employ water quality-related tools. The authors consider that an existing instrument, the Mobile App Rating Scale (MARS) published in 2015 as a tool for assessing the quality of mobile health apps [46], may be suitable for informing, improving, and formalising the process. MARS synthesises a total of 349 app criteria from 25 publications to create six categories for assessment (Supplement 3).

While MARS has been employed as an evaluation tool for numerous health-related smartphone apps $[43,4,44]$, it does not explicitly attend to app features pertaining to GPS/GIS. Unfortunately, this may hinder MARS use by those seeking to evaluate water security-related apps as GPS/GIS features are essential to the provision of spatiotemporallyspecific risk assessments, a capability recommended in this review. Potential evaluation considerations for this additional layer of complexity have been developed to complement the existing MARS framework (Table 6). Those seeking to evaluate apps dependent on location-specific data should consider these GIS/GPS specific criteria, such as the importance of protecting personal data, the ability to enter GPS data using multiple methods (i.e. current location, tagging on map, or typing coordinates) (functionality), ability to set geographic areas of interest for notifications (engagement), or how maps are viewed (aesthetics).

In addition to considering the design, development, and evaluation of private well stewardship smartphone applications, it is important to explore the extent to which this type of smart technology may be scaled across socioeconomic and socio-geographic contexts. Evaluation found that information pertaining to previous uptake of water-related applications was reported for three existing tools. Creekwatch, an American waterway monitoring application launched in 2010, received over 2000 water monitoring reports in its first two years [11]. FreshWater Watch, founded in 2012 and evaluated in 2016, reported over 2000 users across 20 economically diverse regions, including Argentina, Brazil, China, France, India, Malaysia, Mexico, Singapore, and the USA [34]. Collectively, this user cohort submitted over 15,000 water-quality datasets during the first four years of application availability. TransWatL, an SMS-based service for crowdsourcing water-level data in Kenya, provides further evidence that water-related technologies may be adopted in developing regions, receiving over 1000 water-level measurements during its first year [50]. Notwithstanding the presented examples, there are several challenges inherent to implementation of these systems in developing regions of the world where the use of smartphones remains incipient (e.g. India and Bangladesh, where groundwater arsenic is a significant concern). The authors consider that many of these challenges will be nationally and regionally specific, and future studies should both explore and report these challenges in order to streamline developed tools.

Smart-technology use is almost ubiquitous in affluent regions and rapidly increasing at the global scale [27]; thus, smartphone-based well stewardship tools are well positioned to gain traction among private well owners. However, the success of any future private well stewardship application is dependent upon on how user-friendly the design is and how successfully the tool is promoted. To raise awareness of future well stewardship apps, implementers should engage stakeholders who are strategically positioned to influence private well owners and 
Table 5

Components for inclusion in "ideal" private well stewardship app, as informed by the current review.

\begin{tabular}{|c|c|}
\hline Component & Description \\
\hline User account & Mechanism for linking data collected over time; potential to receive water test results through app; privacy protection for individual users and their data \\
\hline Start-up survey & Data collection mechanism for user-inputted data (well characteristics, water treatment, water usage, and maintenance behaviour) \\
\hline GPS co-ordinates & Mechanism for well and aquifer identification; enable hydrogeological risk assessment based on GIS (geology, land use, etc.); link to local weather network \\
\hline Test result entry & Option for users to upload well water quality testing results; log test results over time; potential to link account information and results to databases \\
\hline Risk model & Incorporation of statistical models to estimate contamination risk using inputted data; potential for real time risk updates based on weather events \\
\hline Result sharing & Communication mechanism for risk estimates, result interpretation, recommendations, etc.; employ colour coded symbols and mapping where appropriate \\
\hline Notifications & $\begin{array}{l}\text { Reminders for well maintenance, water quality testing (FIO-based), etc.; alerts for forecasted adverse water quality events (heavy rainfall, localized } \\
\text { contamination) with tips for microbial risk mitigation; notifications for ongoing adverse water quality events (multiple wells in aquifer indicating } \\
\text { contamination) with tips for protecting health }\end{array}$ \\
\hline Resources directory & Access to "how to" guides, service providers, regulatory information, etc. \\
\hline Interface options & Functionality on iOS, Android, and web browsers \\
\hline
\end{tabular}

Table 6

GIS/GPS considerations embedded within MARS framework.

\begin{tabular}{|c|c|}
\hline GIS/GPS Considerations & Primary Source \\
\hline \multicolumn{2}{|c|}{$\begin{array}{l}\text { SECTION A: Engagement - fun, interesting, customisable, interactive (e.g. sends alerts, } \\
\text { messages, reminders, feedback, enables sharing), well-targeted to audience }\end{array}$} \\
\hline Link GPS location to social media for information sharing & [47] \\
\hline Attach media (i.e. video, pictures) to geographic point & [7] \\
\hline Send information to users based on geographic location & [33] \\
\hline Set geographic areas of interest for alerts/notifications & {$[33]$} \\
\hline $\begin{array}{l}\text { Incentivize contribution for crowdsourced geographic } \\
\text { information }\end{array}$ & [47] \\
\hline Map searching, filtering, layering, and customization & [47] \\
\hline \multicolumn{2}{|c|}{$\begin{array}{l}\text { SECTION B: Functionality - app functioning, easy to learn, navigation, flow logic, and } \\
\text { gestural design of app }\end{array}$} \\
\hline $\begin{array}{l}\text { Multiple methods of entering GPS location (i.e. using } \\
\text { current location, tagging on map, or typing } \\
\text { coordinates) }\end{array}$ & [7] \\
\hline $\begin{array}{l}\text { Minimize/simplify GPS data entry requirements (i.e. point } \\
\text { geometry instead of polyline or polygon) }\end{array}$ & {$[2]$} \\
\hline $\begin{array}{l}\text { Intuitive controls (zoom, pan, etc.) that follow operating } \\
\text { system conventions }\end{array}$ & [31] \\
\hline $\begin{array}{l}\text { Automatically save map data when phone interruptions } \\
\text { occur }\end{array}$ & {$[31]$} \\
\hline \multicolumn{2}{|c|}{$\begin{array}{l}\text { SECTION C: Aesthetics - graphic design, overall visual appeal, colour scheme, and stylistic } \\
\quad \text { consistency }\end{array}$} \\
\hline $\begin{array}{l}\text { Simple map design (i.e. minimize map clutter, conservative } \\
\text { and consistent colours, etc.) }\end{array}$ & [31] \\
\hline Use collapsible legends, control containers, etc. & [16] \\
\hline Responsive map design to fit different screen sizes & {$[42]$} \\
\hline \multicolumn{2}{|c|}{$\begin{array}{l}\text { SECTION D: Information - Contains high quality information (e.g. text, feedback, measures, } \\
\text { references) from a credible source. Select N/A if the app component is irrelevant }\end{array}$} \\
\hline Indicate current location of user on map & {$[31]$} \\
\hline Mechanism to validate GPS location entered by users & [47] \\
\hline Indicate GPS strength/accuracy for locations set by users & [7] \\
\hline Data viewing options (on map or in list view) & [3] \\
\hline Real time map updates & [33] \\
\hline \multicolumn{2}{|l|}{ Additional Considerations } \\
\hline Privacy protection for users who volunteer information & {$[33]$} \\
\hline Tutorials/training/help integrated into app to assist users & [3] \\
\hline
\end{tabular}

promote uptake, especially those in positions of trust, rather than authority. Nationally and regionally appropriate public health agencies and laboratories, local authorities, government agencies, well inspectors, hydro(geo)logists, engineering contractors/consultants and entities specializing in well drilling and maintenance should be seen as potential implementation partners. Moreover, any developed tool of this nature should be viewed as a consumer product and, as such, development and implementation should comprise appropriate partners including retail, marketing, and promotional experts, in order to ensure that business/product implementation and "roll out" are successful.

\section{Conclusions}

This review assessed the current scope and capabilities of water quality-related smartphone apps and web-based tools. Among the 35 eligible tools, apps for both data collection and risk communication were identified. Notably, no existing water-related app was considered to have the capacity to assess risk via user-defined inputs. In looking to the future, smartphone apps employing data collection, source-specific risk assessment, and risk communication are being developed as potential mechanisms to improve private well stewardship. As the utility of "pocket technologies" for private water source management is further realized, future app development will inevitably follow, leading to tools serving diverse geographic regions and water source types. If implemented and evaluated effectively, an "ideal" app can provide an effective and low-cost knowledge translation medium, bolstering private well stewardship and reducing the burden of water-related illness.

To this end, several pertinent conclusions emerge from this review. Firstly, widespread comfort with, and access to, web-based tools and smartphone apps have created an opportunity to extend robust evidence-based stewardship tools directly to individuals and households. While water quality-related tools were classified into two broad classes, namely data collection and risk communication, the opportunity exists to develop a new tool category, which will employ models to combine data collection and risk prediction. Tools of this nature may be used to overcome limitations associated with generalized risk mitigation recommendations by providing users with spatiotemporally specific information. Furthermore, future private well stewardship apps will require user engagement and should incorporate user accounts, start-up surveys, GPS location, test result entry, risk prediction algorithms, results sharing, notifications, and functionality across all interface options. Future applications should target modelling pathogen-related health risks to well water consumers and provision of tailored mitigation strategies. To ensure effective rollout of new private well stewardship apps, initiatives must include evaluations that incorporate user uptake and feedback, as well as the accuracy and functionality of app outputs.

These conclusions should inform the development of future private well stewardship tools dedicated to reducing the health burden of water-related illness. A tool of this nature aligns with the recommendations of both the CDC's Clean Water for Health Program and the recent recommendation in the SDG 6 synthesis report to embrace data and smart technologies to improve water management. Advancements in this domain will bring previously inaccessible data, technology, and tools directly to private well owners, who previously managed their private systems in virtual isolation. Ultimately, the aim is to facilitate well stewardship by introducing a mechanism (smartphone app) that will address both the physical and social dimensions of well stewardship. By integrating context-specific pathogenic risk information with a mechanism to engage private well owners, consumers will be mobilized towards risk mitigation, thereby reducing the burden of waterborne illness linked to private well contamination. 


\section{Acknowledgements}

Dr. R. Stephen Brown of Queen's University contributed to the conceptualization of this review. T. Hoffman was a student in the Department of Public Health Sciences at Queen's University, completing an internship at Public Health Ontario, while undertaking this work.

\section{Funding}

Funding for this initiative was provided in part by Public Health Ontario and Empire Life.

\section{Declarations of interest}

None.

\section{Appendix A. Supplementary data}

Supplementary data to this article can be found online at https:// doi.org/10.1016/j.wasec.2019.100026.

\section{References}

[1] L. Andrade, J. O'Dwyer, E. O'Neill, P. Hynds, Surface water flooding, groundwater contamination, and enteric disease in developed countries: a scoping review of connections and consequences, Environ. Pollut. 236 (2018) 540-549.

[2] I. Ariffin, B. Solemon, R.M. Anwar, M.M. Din, N.N. Azmi, Exploring the potentials of volunteered geographic information as a source for spatial data acquisition, IOP Conference Series: Earth and Environmental Science (Vol. 20, No. 1), IOP Publishing, 2014, p. 012041.

[3] I. Ariffin, B. Solemon, W. Bakar, An evaluative study on mobile crowdsourcing applications for crime watch, 2014 International Conference on Information Technology and Multimedia, (2014).

[4] L. Boyle, R. Grainger, R.M. Hall, J.D. Krebs, Use of and beliefs about mobile phone apps for diabetes self-management: surveys of people in a hospital diabetes clinic and diabetes health professionals in New Zealand, JMIR mHealth uHealth 5 (6) (2017).

[5] H. Chappells, N. Campbell, J. Drage, C.V. Fernandez, L. Parker, T.J. Dummer, Understanding the translation of scientific knowledge about arsenic risk exposure among private well water users in Nova Scotia, Sci. Total Environ. 505 (2015) 1259-1273.

[6] J.W. Charrois, Private drinking water supplies: challenges for public health, Can. Med. Assoc. J. 182 (10) (2010) 1061-1064.

[7] J. Clark, Location Gathering: An Evaluation of Smartphone-Based Geographic Mobile Field Data Collection Hardware and Applications (Unpublished Master's Thesis), San Jose State University, San Jose, California, 2015.

[8] D. Davies, Meet the 7 Most Popular Search Engines in the World, (2018) Retrieved from https://www.searchenginejournal.com/seo-101/meet-search-engines/.

[9] S. DiPelino, C.J. Schuster Wallace, S.E. Dickson-Anderson, P.D. Hynds, A. Majury, A coupled systems framework for managing microbial risk in private drinking water wells, Can. J. Water Resour. Manage. (2019) (Accepted for Publication).

[10] S. Elgert, Rural Water Quality Information Tool. Canadian Society for Bioengineering, Annual Conference, Paper No CSBE15-121, July 2015.

[11] B.J. Eck, Smartphones for urban hydrology: an analysis of Creekwatch observations, AGU Fall Meeting Abstracts, (2012).

[12] M.N. Fienen, C.S. Lowry, Social. Water - a crowdsourcing tool for environmental data acquisition, Comput. Geosci. (2012), https://doi.org/10.1016/j.cageo.2012. 06.015 .

[13] S.V. Flanagan, R.G. Marvinney, Y. Zheng, Influences on domestic well water testing behavior in a Central Maine area with frequent groundwater arsenic occurrence, Sci. Total Environ. 505 (2015) 1274-1281.

[14] M.A. Fox, K.E. Nachman, B. Anderson, J. Lam, B. Resnick, Meeting the public health challenge of protecting private wells: proceedings and recommendations from an expert panel workshop, Sci. Total Environ. 554 (2016) 113-118..

[15] General Assembly resolution 64/292, The Human Right to Water and Sanitation, A/ RES/64/292 (28 July 2010), Available from http://www.un.org/en/ga/search/ view_doc.asp? symbol = A/RES/64/292.

[16] C. Gkonos, I. Iosifescu Enescu, L. Hurni, Spinning the wheel of design: evaluating geoportal Graphical User Interface adaptations in terms of human-centred design, Int. J. Cartogr. (2018) 1-21.

[17] K. Godin, J. Stapleton, S.I. Kirkpatrick, R.M. Hanning, S.T. Leatherdale, Applying systematic review search methods to the grey literature: a case study examining guidelines for school-based breakfast programs in Canada, Syst. Rev. 4 (1) (2015) 138.

[18] H.G. Gorchev, G. Ozolins, WHO guidelines for drinking-water quality, WHO Chronicle 38 (3) (2011) 104-108, https://doi.org/10.1016/S1462-0758(00) 00006-6.
[19] M.J. Grant, A. Booth, A typology of reviews: an analysis of 14 review types and associated methodologies, Health Inform. Libraries J. 26 (2) (2009) 91-108.

[20] B. Guzman-Herrador, A. Carlander, S. Ethelberg, B.F. de Blasio, M. Kuusi, V. Lund, et al., Waterborne outbreaks in the Nordic countries, 1998 to 2012, Eurosurveillance 20 (24) (2015) 21160.

[21] P.D. Hynds, B.D. Misstear, L.W. Gill, Development of a microbial contamination susceptibility model for private domestic groundwater sources, Water Resour. Res. 48 (12) (2012)

[22] P.D. Hynds, B.D. Misstear, L.W. Gill, Unregulated private wells in the Republic of Ireland: consumer awareness, source susceptibility and protective actions, J. Environ. Manage. 127 (2013) 278-288.

[23] P.D. Hynds, S. Regan, E. Mooney, Jean O'Dwyer, Development of a Pocket Technology Groundwater Risk Application for Local Evaluation (GRAppLE) in Highly Groundwater Reliant Populations, 2018, https://doi.org/10.13140/RG.2.2. 23484.33928.

[24] P. Hynds, O. Naughton, E. O'Neill, S. Mooney, Efficacy of a national hydrological risk communication strategy: domestic wastewater treatment systems in the Republic of Ireland, J. Hydrol. 558 (2018) 205-213.

[25] International Telecommunication Union, Measuring the Information Society 2017 Volume 2. ICT Country Profiles, Retrieved from ITU, Geneva, 2017https://www.itu. int/en/ITU-D/Statistics/Documents/publications/misr2017/MISR2017_Volume1. pdf.

[26] A.Q. Jones, C.E. Dewey, K. Doré, S.E. Majowicz, S.A. McEwen, D. Waltner-Toews, E. Mathews, Public perception of drinking water from private water supplies: focus group analyses, BMC Public Health 5 (1) (2005) 129.

[27] S. Kemp, Digital in 2018: World's Internet Users Pass the 4 Billion Mark, Retrieved from (2018) https://wearesocial.com/blog/2018/01/global-digital-report-2018.

[28] S. Kim, C. Robson, T. Zimmerman, J. Pierce, E.M. Haber, Creek watch: pairing usefulness and usability for successful citizen science, Proceedings of the SIGCHI Conference on Human Factors in Computing Systems, ACM, 2011, pp. 2125-2134.

[29] R. Kreutzwiser, R. de Loë, K. Imgrund, M.J. Conboy, H. Simpson, R. Plummer, Understanding stewardship behaviour: factors facilitating and constraining private water well stewardship, J. Environ. Manage. 92 (4) (2011) 1104-1114.

[30] J. Krolik, G. Evans, P. Belanger, A. Maier, G. Hall, A. Joyce, A. Majury, Microbial source tracking and spatial analysis of E. coli contaminated private well waters in southeastern Ontario, J. Water Health 12 (2) (2014) 348-357.

[31] L. Kuparinen, Validation and extension of the usability heuristics for mobile map applications, ICC \& GIS 2016: Proceedings of the 6th International Conference on Cartography \& GIS (Vol. 1 and 2), Bulgarian Cartographic Association, 2016.

[32] T. Leeuw, E. Boss, The hydrocolor app: above water measurements of remote sensing reflectance and turbidity using a smartphone camera, Sensors 18 (1) (2018) 256.

[33] L. Li, M.N. Ulaganathan, Design and development of a crowdsourcing mobile app for disaster response, Geoinformatics, 2017 25th International Conference on, IEEE, 2017, pp. 1-4.

[34] S. Loiselle, I. Thornhill, N. Bailey, Citizen science: advantages of shallow versus deep participation, Front. Environ. Sci. Conf. Abstr. Austrian Citiz. Sci. Conf. (Vol. 2016), 2016, p. 4.

[35] C.S. Lowry, M.N. Fienen, CrowdHydrology: crowdsourcing hydrologic data and engaging citizen scientists, GroundWater 51 (1) (2013) 151-156.

[36] A. Maier, J. Krolik, K. Randhawa, A. Majury, Bacteriological testing of private well water: a trends and guidelines assessment using five years of submissions data from southeastern Ontario, Can. J. Public Health 105 (3) (2014) e203-8.

[37] K.M. Malecki, A.A. Schultz, D.J. Severtson, H.A. Anderson, J.A. VanDerslice, Private-well stewardship among a general population based sample of private wellowners, Sci. Total Environ. 601 (2017) 1533-1543.

[38] L. Morris, S. Wilson, W. Kelly, Methods of conducting effective outreach to private well owners - a literature review and model approach, J. Water Health 14 (2) (2016) 167-182.

[39] H.M. Murphy, M.D. Prioleau, M.A. Borchardt, P.D. Hynds, Review: epidemiological evidence of groundwater contribution to global enteric disease, 1948-2015, Hydrogeol. J. 25 (4) (2017) 981-1001, https://doi.org/10.1007/s10040-0171543-y.

[40] S. Novoa, M. Wernand, H.J. van der Woerd, WACODI: a generic algorithm to derive the intrinsic color of natural waters from digital images, Limnol. Oceanogr. Methods 13 (12) (2015) 697-711.

[41] M.P. Paul, P. Rigrod, S. Wingate, M.E. Borsuk, A community-driven intervention in Tuftonboro, New Hampshire, succeeds in altering water testing behavior, J. Environ. Health 78 (5) (2015) 30.

[42] R.E. Roth, Interactivity and cartography: a contemporary perspective on user interface and user experience design from geospatial professionals, Cartographica 50 (2) (2015) 94-115.

[43] K. Santo, S.S. Richtering, J. Chalmers, A. Thiagalingam, C.K. Chow, J. Redfern, Mobile phone apps to improve medication adherence: a systematic stepwise process to identify high-quality apps, JMIR mHealth uHealth 4 (4) (2016).

[44] S. Schoeppe, S. Alley, A.L. Rebar, M. Hayman, N.A. Bray, W. Van Lippevelde, et al, Apps to improve diet, physical activity and sedentary behaviour in children and adolescents: a review of quality, features and behaviour change techniques, Int. J. Behav. Nutr. Phys. Activity 14 (1) (2017) 83.

[45] A.B. Scott, P.C. Frost, Monitoring water quality in Toronto's urban stormwater ponds: assessing participation rates and data quality of water sampling by citizen scientists in the FreshWater Watch, Sci. Total Environ. 592 (2017) 738-744.

[46] S.R. Stoyanov, L. Hides, D.J. Kavanagh, O. Zelenko, D. Tjondronegoro, M. Mani, Mobile app rating scale: a new tool for assessing the quality of health mobile apps, JMIR mHealth uHealth 3 (1) (2015).

[47] Z. Tang, T. Liu, Evaluating Internet-based public participation GIS (PPGIS) and 
volunteered geographic information (VGI) in environmental planning and management, J. Environ. Plann. Manage. 59 (6) (2016) 1073-1090.

[48] United Nations, Sustainable Development Goal 6 Synthesis Report on Water and Sanitation, Retrieved from (2018) http://www.unwater.org/publications/ highlights-sdg-6-synthesis-report-2018-on-water-and-sanitation-2/.
[49] I.H.J. van Meerveld, J. Seibert, M. Vis, S. Etter, B. Strobl, CrowdWater - can people observe what models need? AGU Fall Meeting Abstracts, (2017).

[50] B. Weeser, J.S. Kroese, S.R. Jacobs, N. Njue, Z. Kemboi, A. Ran, et al., Citizen science pioneers in Kenya - a crowdsourced approach for hydrological monitoring, Sci. Total Environ. 631 (2018) 1590-1599. 